\title{
Salivary cortisol and $\alpha$-amylase: subclinical indicators of stress as cardiometabolic risk
}

\author{
S. Cozma ${ }^{1^{*}}$, L.C. Dima-Cozma ${ }^{2^{*}}$, C.M. Ghiciuc $3^{3^{*}}$, V. Pasquali ${ }^{4^{\star}}$, A. Saponaro $5^{5^{*}}$ and \\ ${ }^{1}$ Department of Otorhinolaryngology, School of Medicine, University of Medicine and Pharmacy "Grigore T. Popa”, lasi, Romania \\ ${ }^{2}$ Department of Internal Medicine, School of Medicine, University of Medicine and Pharmacy "Grigore T. Popa", lasi, Romania \\ ${ }^{3}$ Department of Pharmacology, School of Medicine, University of Medicine and Pharmacy "Grigore T. Popa", lasi, Romania \\ ${ }^{4}$ Department of Psychology, Sapienza University of Rome, Rome, Italy \\ ${ }^{5}$ Department of Physiology and Pharmacology “V. Erspamer”, Sapienza University of Rome, Rome, Italy
}

\begin{abstract}
Currently, the potential for cardiovascular (CV) stress-induced risk is primarily based on the theoretical (obvious) side effects of stress on the CV system. Salivary cortisol and $\alpha$-amylase, produced respectively by the hypothalamus-pituitary-adrenal (HPA) axis and the sympathetic-adrenomedullary (SAM) system during stress response, are still not included in the routine evaluation of $\mathrm{CV}$ risk and require additional and definitive validation. Therefore, this article overviews studies published between 2010 and 2015 , in which salivary cortisol and $\alpha$-amylase were measured as stress biomarkers to examine their associations with CV/CMR (cardiometabolic risk) clinical and subclinical indicators. A comprehensive search of PubMed, Web of Science and Scopus electronic databases was performed, and 54 key articles related to the use of salivary cortisol and $\alpha$-amylase as subclinical indicators of stress and CV/CMR factors, including studies that emphasized methodological biases that could influence the accuracy of study outcomes, were ultimately identified. Overall, the biological impact of stress measured by salivary cortisol and $\alpha$-amylase was associated with CV/CMR factors. Results supported the use of salivary cortisol and $\alpha$-amylase as potential diagnostic tools for detecting stress-induced cardiac diseases and especially to describe the mechanisms by which stress potentially contributes to the pathogenesis and outcomes of CV diseases.
\end{abstract}

Key words: Salivary stress biomarkers; Cardiometabolic risk (factors); Stress; Hypothalamic-pituitary-adrenal axis; Sympathetic adrenomedullary system

\section{Introduction}

Cardiometabolic risk (CMR) refers to risk factors that increase the likelihood of experiencing vascular events or of developing metabolic disease $(1,2)$. In addition to traditional cardiovascular (CV) risk factors (age, gender, family history, hypertension, dysglycemia, dyslipidemia, and smoking), CMR factors include abdominal obesity, insulin resistance, inflammation, lack of consumption of fruits and vegetables, sedentary lifestyle, and especially stress, an important component of modern life that has become a significant health problem in the general population $(3,4)$.

Currently, we use the word "stress" to describe the feeling of being overwhelmed by the psychophysical stressinduced challenges of daily life; this feeling may be highly adaptive from an evolutionary point of view because it allows us to cope with similar circumstances in the future. For the sake of brevity and to avoid delving too far into the details of the evolution of the concept of stress that has occurred over the past few centuries, we will refer to the modern and very comprehensive proposal that was put forth by Bruce McEwen to explain the complexity of the stress response (5-8). This proposal can be synthesized by the expressions "to be stressed" and "to be stressed out", which distinguish good stress challenges from bad stress challenges. According to McEwen's proposal, the pathophysiology of the stress response can be described by the concept of allostasis, which is the process of achieving stability (or homeostasis) through physiological or behavioral change. Allodynamic processes can be adaptive in the short term (allostasis) and maladaptive in the long term (allostatic load). The identity of the factors that determine the threshold between adaptive and maladaptive responses to stressors remains an open question for researchers in the field of stress. This question highlights the need to

Correspondence: F.R. Patacchioli: < francesca.patacchioli@uniroma1.it>

*These authors contributed equally to this study.

Received June 8, 2016 | Accepted November 23, 2016 
search for predictive biomarkers of the risk of developing stress-related diseases.

Activation of the hypothalamic-pituitary-adrenal (HPA) axis and sympathetic adrenomedullary (SAM) system is essentially an adaptive mechanism that enables the human body to maintain physiological stability in response to general stress signals. Complex reciprocal counterbalances between the HPA axis and SAM system have been described, and stress-induced chronic stimulation and dysregulation of these systems may cause metabolic abnormalities (8-13).

Substantial evidence indicates that chronic elevation of cortisol levels and dysfunction of the feedback system within the HPA axis play a prominent role in stress responses $(14,15)$. However, the opposite has also been clearly shown as the hyporesponsive HPA axis has been linked to increased susceptibility to chronic illness (16-18).

Salivary levels of free cortisol are characterized by circadian fluctuation; concentrations in the morning are significantly higher than those in the evening. The cortisol awakening response (CAR) refers to the typical production of cortisol that occurs upon awakening. As part of a cycle within a cycle, the CAR reflects the changes in cortisol concentration that occur during the first hour after waking from sleep in the morning $(11,18-21)$.

Activation of the SAM system may induce pathophysiological changes in cardiovascular activity that range from a mere increase in heart rate $(H R)$, blood pressure (BP) and free fatty acids in healthy subjects to the induction of angina, myocardial infarction, ventricular arrhythmia and acute heart failure in patients with significant coronary lesions $(22,23)$. The search for a "cortisol-like" non-invasive and easily obtainable marker of SAM activation led to the identification of salivary $\alpha$-amylase as a promising candidate because its secretion is under strong neurohormonal control (24-26).

Currently, the potential for CV stress-induced risk is primarily based on the theoretical (obvious) side effects of stress on the cardiovascular system. Furthermore, while CV/CMR factors are routinely assessed in clinical practice, saliva-based biomarkers produced by HPA axis/SAM system (dys)function during stress response are still not included in the routine evaluation of cardiovascular risk and require additional and definitive validation. Therefore, this article overviews studies published between 2010 and 2015 related to the use of salivary cortisol and $\alpha$-amylase as subclinical indicators of stress, and as CV/CMR factors, including studies that emphasized methodological biases that could influence the accuracy of study outcomes.

\section{Material and Methods}

Eligible studies were original research articles published in peer-reviewed journals between January 2010 and December 2015 and identified through searches of the PubMed, Web of Science and Scopus electronic databases (27). We included studies if they involved human subjects in which salivary cortisol and $\alpha$-amylase were measured as stress biomarkers to examine the associations with CV/CMR clinical and subclinical indicators. The term "cardiometabolic risk (factor)" was paired with "stress", "psychological stress", "stress hormones", "salivary cortisol", "salivary $\alpha$-amylase", "hypothalamuspituitary-adrenal (HPA) axis ", and "sympathetic adrenomedullary (SAM) system". A flow chart describing the process of study identification is shown in Figure 1. During Skype conferences, all coauthors did the search through repeated use of the words in different combinations. Studies were included only if they assessed stress-induced response either to laboratory challenges, psychosocial items and/or diseases in different populations by measuring salivary cortisol and/or salivary $\alpha$-amylase as well as clinical/ subclinical indicators of CV/CMR.

The initial search yielded 569 titles. In addition, 30 supplementary titles were included by scanning the reference lists of retrieved papers. All abstracts were independently read by each coauthor: 408 non-human studies, reviews, letters, editorials, and non-English language reports were excluded. From the remaining 191 abstracts, all full manuscripts were gathered and were independently reviewed by each coauthor for key information. One hundred and thirty-seven studies were excluded because they were not relevant to the purpose of the review, since: a) they did not report salivary cortisol and/or $\alpha$-amylase assessment, or b) because they evaluated stress response through psychometric tools only, or c) they considered the occurrence of stressful events itself as a CV/CMR factor without any salivary stress biomarker assessment.

All coauthors independently assessed eligibility by reviewing full text articles; if any coauthor was unsure whether an article met eligibility criteria, the article was discussed among the research team and full agreement was always reached. As shown in the flow chart of the literature selection process (Figure 1), 54 key articles were ultimately identified to be reviewed in this paper. Among these key articles, 46 were related to the stress-induced modification of the HPA axis and SAM system associated with variation in subclinical and clinical indicators of $\mathrm{CV} / \mathrm{CMR}$, and 8 addressed crucial methodological issues.

\section{Results}

Supplementary Table S1 includes stressor, CV/CMR subclinical and clinical indicators, salivary biomarker measured, and a summary of the outcomes for each selected study. Sources of stress varied across studies. Stressors included mental task challenges, job strain and work shift, sport competition, effort test, ambulatory surgical stress, hypobaric hypoxia, and hypoxia and sleep fragmentation induced by obstructive sleep apnea in obese subjects. 
Figure 1. Literature selection method.

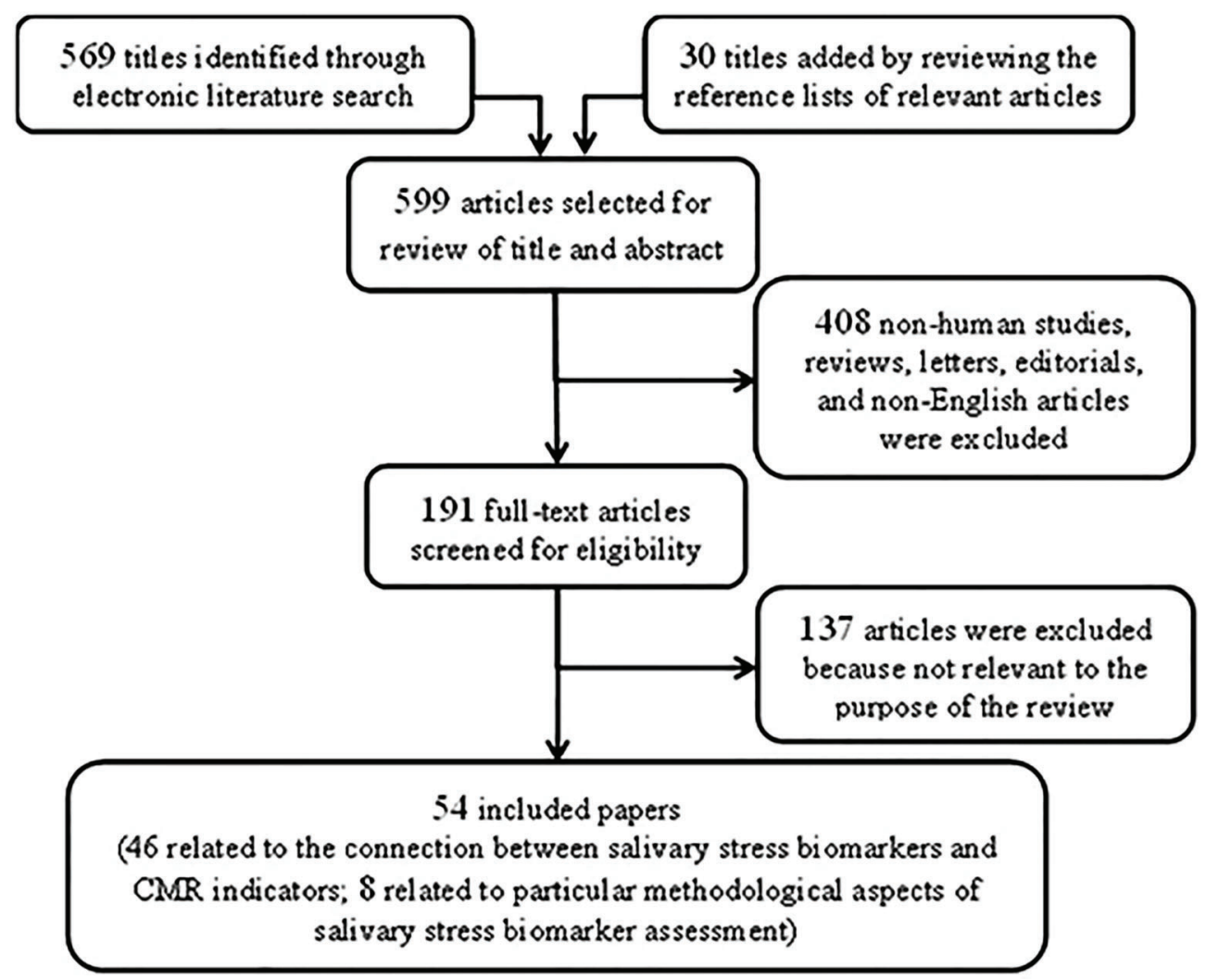

Table 1. Selected studies concerning methodological aspects of salivary stress biomarker assessment.

\begin{tabular}{|c|c|c|}
\hline Author, Year & Saliva-based stress biomarkers & Methodological recommendation \\
\hline Bosch et al. (25) 2011 & $\alpha$-Amylase & Salivary flow rate contribution \\
\hline Ghiciuc et al. (20) 2011 & Cortisol \& $\alpha$-Amylase & Adherence to salivary collection protocol \\
\hline Hall et al. (73) 2012 & Cortisol & Adherence to salivary collection protocol \\
\hline Inder et al. (74) 2012 & Cortisol & Laboratory assessment techniques \\
\hline Sanchez et al. (75) 2012 & Cortisol & $\begin{array}{l}\text { Mathematical/statistical methods applied to salivary } \\
\text { stress biomarker assessment }\end{array}$ \\
\hline Nater et al. (76) 2013 & Cortisol \& $\alpha$-Amylase & Adherence to salivary collection protocol \\
\hline Russell et al. (77) 2015 & Cortisol & Inter-laboratory round-robin standardization \\
\hline Stalder et al. (78) 2016 & Cortisol & General guidelines for the assessment of salivary biomarkers \\
\hline
\end{tabular}

Researchers studied salivary cortisol $(11,28,30-34$, $37-40,42-47,49-54,56-68,70,71)$ and/or salivary $\alpha$-amylase response to stress $(11,29,32,33,35,36,40-42,44,48,49$, $52,53,55,59,61,63,66,69-72)$ for their association with $\mathrm{CV} / \mathrm{CM}$ items. A substantial number of these studies showed significant correlations between salivary cortisol and/or salivary $\alpha$-amylase and clinical/subclinical CV/CMR indicators $(28,29,31,32,36,37,44,50,55)$. Several studies have demonstrated the association between stress-induced salivary cortisol and/or salivary $\alpha$-amylase modifications and CV/CMR clinical/subclinical indicators $(11,35,47,70,71)$.

Numerous methodological factors (biological and procedural/analytical) can influence saliva-based human neuro-endocrine measurements and, consequently, can dramatically compromise the accuracy and validity of research.

Table 1 lists studies providing an overview of the methodological recommendations that must be considered to prevent the danger of obtaining biased results when 
assessing salivary cortisol and/or salivary $\alpha$-amylase as stress biomarkers. For example, nonadherence to the saliva collection protocol or invisible traces of blood can interfere with the results of saliva testing (78). Ecological momentary assessment studies provide reproducible and reliable evaluation of stress biomarkers that can be even improved through multiple sampling $(20,73,76,78)$ and that, in contrast to blood sampling, can be easily achieved through saliva-based testing strategy. However, food intake should be restricted to $1-2 \mathrm{~h}$ prior to saliva sampling. Water intake does not affect test results, although coffee/alcohol and other drinks are not recommended (78). In addition, all other factors that influence salivary flow rate must be taken into account especially when salivary $\alpha$-amylase is assayed as a non-invasive marker for SAM system activity (25). Other efforts to reduce bias include the development of specific and standardized analytical tools (74), the establishment of defined reference intervals, and the implementation of round-robin trials (75-77). However, the lack of compliance that sometimes occurs with outpatient saliva donors requires strict standardization of both collection and analysis methods to improve the possibility of comparing salivary biomarker data $(20,73,76,78)$.

\section{Discussion}

The purpose of this study was to provide a literature overview regarding the use of saliva-based stress biomarkers to explore the association of stress with CV/CMR indicators. Physiological stress response also includes a general arousal component that is associated with reactivity of the HPA axis/SAM system and is respectively measurable via salivary cortisol and via autonomic nervous system indices such as salivary $\alpha$-amylase.

Articles have reported and discussed individual salivary cortisol and/or $\alpha$-amylase differences in response to acute stress challenge (laboratory stress, i.e., under controlled conditions) that may be useful to underlie some of the subjective differences in CV/CM stress-induced vulnerabilities in healthy populations as well as in people with advanced CV/CM diseases $(28,50,64)$. We have also reported studies supporting the connection between stress-induced allostatic (over)load and the appearance of more or less severe CV/CM disorders $(37,47,50,51,53$, $56,57,64,65)$.

We found that the biological impact of stress measured by salivary cortisol and $\alpha$-amylase was associated with $\mathrm{CV} / \mathrm{CMR}$ factors. Taken together, the studies included in the present literature review suggest that changes in salivary cortisol and $\alpha$-amylase concentrations, as well as their diurnal fluctuations, may have general implications for providing further biological mechanisms by which stress (overload) can be considered itself as a CV/CMR factor.

In agreement with previous speculations that HPA axis/SAM system dysfunction can potentially result in CV/CM diseases (79-82), the reports included in this review showed that several patterns of (acute/chronic) stress-induced production of salivary cortisol and/or salivary $\alpha$-amylase are associated with abnormal HPA axis and SAM system activities, often concomitant with an unhealthy lifestyle, and potentially having detrimental effects on the CV system.

Monitoring activities of the SAM system and HPA axis is particularly important for the study of adaptive mechanisms of the autonomic and HPA stress resilience (32).

Salivary free cortisol is a well-known marker of HPA axis activity and plays a crucial role in an organism's efforts to respond/adapt to stressors (15). The major advantage of salivary $\alpha$-amylase measurements over other parameters that reflect SAM system activity (i.e., CV activity measures or skin conductance) is that it is measured in saliva and therefore allows ecological momentary assessments.

Although saliva has not yet become a common sample source for the analysis of saliva-based stress biomarkers, this evolving field of research represents a reliable method of investigating HPA axis and SAM activity, providing a means to avoid the stressful event of venipuncture and offering the possibility of self-collection by subjects.

Previous studies from other groups as well as from our own have shown that the collection of saliva provides a noninvasive, stress-free, reliable source for monitoring the human body's stress response, even in real life context, in different pathophysiological conditions without requiring the assistance of medical staff. Since 1983 (84) and thereafter, salivary cortisol concentration was found to be directly proportional to the serum unbound cortisol concentration both in normal men and women and in women with elevated cortisol-binding globulin. The correlation was excellent in dynamic tests of adrenal function (dexamethasone suppression, ACTH stimulation), in healthy subjects and in patients with adrenal insufficiency, in tests of circadian variation and in randomly collected samples. Women in the third trimester of normal pregnancy exhibited elevated salivary cortisol throughout the day. The rate of equilibrium of cortisol between blood and saliva was very fast, being less than 5 minutes. Since only free levels of cortisol are detected in saliva, salivary cortisol is suggested to be a more appropriate measure for the clinical assessment of adrenocortical function than serum cortisol $(11,18,20,25,26,37,67,70,74,76,83-85)$.

Regarding salivary $\alpha$-amylase, this biomarker is measured exclusively in saliva. During recent years, a growing interest emerged in using salivary $\alpha$-amylase as a non-invasive, surrogate marker for sympathetic activity. Salivary $\alpha$-amylase has been proposed as a sensitive biomarker for stress-related changes in the body that reflect the activity of the sympathetic nervous system, and a growing body of research is accumulating to support the validity and reliability of this parameter. Numerous studies applying stress protocols have demonstrated that salivary $\alpha$-amylase is highly sensitive to stress-related changes. 
This field of research is still in its early stages. However, the studies included in our review further support the evidence that the employment of salivary $\alpha$-amylase as an indicator of the SAM system (dys)-regulation is promising. Nevertheless, considerable long-term effort is still required for this approach to receive acceptance, especially by clinicians. Thus, actions to improve reliability can assist researchers in reducing measurement outcome variance of saliva-based stress biomarkers assessment and increase the validity of provided pathophysiological data, contributing to improving the interpretation and understanding of study results.

The main message of this overview is in support of the use of saliva-based stress biomarker assessment, not only in research but also in clinical practice. Indeed, in our literature review, we did not identify a single clear objection to the use of saliva as a diagnostic fluid, although we did identify strict methodological recommendations to avoid factors that influence and add variance to saliva-based stress biomarker measurement outcomes.

Stress-induced symptoms are malleable; they can affect different body systems and overlap between one

\section{References}

1. Chatterjee A, Harris SB, Leiter LA, Fitchett DH, Teoh $H$, Bhattacharyya $\mathrm{OK}$, et al. Managing cardiometabolic risk in primary care: summary of the 2011 consensus statement. Can Fam Physician 2012; 58: 389-393.

2. Greenland P, Alpert JS, Beller GA, Benjamin EJ, Budoff MJ, Fayad ZA, et al. 2010 ACCF/AHA guideline for assessment of cardiovascular risk in asymptomatic adults: executive summary: a report of the American College of Cardiology Foundation/American Heart Association Task Force on Practice Guidelines. Circulation 2010; 122: 2748-2764, doi: 10.1161/CIR.0b013e3182051bab.

3. Sheps DS, McMahon RP, Becker L, Carney RM, Freedland $\mathrm{KE}$, Cohen JD, et al. Mental stress-induced ischemia and all-cause mortality in patients with coronary artery disease: results from the psychophysiological investigations of myocardial ischemia study. Circulation 2002; 105: 1780-1784, doi: 10.1161/01.CIR.0000014491.90666.06.

4. Rosengren A, Hawken S, Ounpuu S, Sliwa K, Zubaid M, Almahmeed WA, et al. Association of psychosocial risk factors with risk of acute myocardial infarction in 11119 cases and 13648 controls from 52 countries (the INTERHEART study): case-control study. Lancet 2004; 364 : 953-962, doi: 10.1016/S0140-6736(04)17019-0.

5. McEwen BS. Protective and damaging effects of stress mediators. New Engl J Med 1998; 338: 171-179, doi: 10.1056/ NEJM199801153380307.

6. McEwen BS. Mood disorders and allostatic load. Biol Psychiatry 2003; 54: 200-207, doi: 10.1016/S0006-3223 (03)00177-X.

7. McEwen BS. Protective and damaging effects of stress mediators: central role of the brain. Dialogues Clin Neurosci 2006; 8: 367-381. type of disorder and another. Therefore, stress management strategies are frequently complex and need to be matched to the requirements of individual patients, beginning with the presumably positive diagnosis of a stressinduced disorder and continuing through rehabilitation and training to cope with distress. The use of validated saliva-based biomarkers as indicators of stress-induced body system vulnerability (allostatic overload) could support patients in improving their strategies to cope with challenging life events, through non-pharmacological approaches $(11,58,86-88)$.

\section{Supplementary Material}

Click here to view [pdf].

\section{Acknowledgments}

This study was partially supported by the University of Medicine and Pharmacy "Grigore T. Popa" - lasi through grant No. 29234/December 20, 2013 to L.C. Dima-Cozma.

8. McEwen BS. Physiology and neurobiology of stress and adaptation: Central role of the brain. Physiol Rev 2007; 87: 873-904, doi: 10.1152/physrev.00041.2006.

9. Cortelli P, Parchi P, Sforza E, Contin M, Pierangeli G, Barletta G, et al. Cardiovascular autonomic dysfunction in normotensive awake subjects with obstructive sleep apnoea syndrome. Clin Auton Res 1994; 4: 57-62, doi: $10.1007 / B F 01828839$.

10. Cortelli P, Lombardi C, Montagna P, Parati G. Baroreflex modulation during sleep and in obstructive sleep apnea syndrome. Auton Neurosci 2012; 169: 7-11, doi: 10.1016/ j.autneu.2012.02.005.

11. Ghiciuc CM, Dima-Cozma LC, Bercea RM, Lupusoru CE, Mihaescu T, Szalontay A, et al. Restoring of salivary cortisol awakening response (CAR) by nasal continuous positive airway pressure (CPAP) therapy in obstructive sleep apnea. Chronobiol Intern 2013; 30: 124-131, doi: 10.3109/07420 528.2013.795155.

12. Boutzios G, Kaltsas G. Clinical syndromes related to gastrointestinal neuroendocrine neoplasms. Front Horm Res 2015; 44: 40-57, doi: 10.1159/issn.0301-3073.

13. Calandra-Buonaura G, Provini F, Guaraldi P, Plazzi G, Cortelli P. Cardiovascular autonomic dysfunctions and sleep disorders. Sleep Med Rev 2015; 26: 43-56, doi: 10.1016/ j.smrv.2015.05.005.

14. Burke HM, Davis MC, Otte C, Mohr DC. Depression and cortisol responses to psychological stress: a meta-analysis. Psychoneuroendocrinology 2005; 30: 846-856, doi: 10.1016/ j.psyneuen.2005.02.010.

15. Hellhammer DH, Wüst S, Kudielka BM. Salivary cortisol as a biomarker in stress research. Psychoneuroendocrinology 2009; 34: 163-171, doi: 10.1016/j.psyneuen.2008.10.026. 
16. Buske-Kirschbaum A, Aurer K, von Krieger S, Weiss S, Rauh W, Hellhammer D. Blunted cortisol responses to psychosocial stress in asthmatic children: a general feature of atopic disease? Psychosom Med 2003; 65: 806-810, doi: 10.1097/01.PSY.0000095916.25975.4F.

17. Adam EK, Kumari M. Assessing salivary cortisol in largescale, epidemiological research. Psychoneuroendocrinology 2009; 34: 1423-1436, doi: 10.1016/j.psyneuen.2009. 06.011.

18. Delle Chiaie R, Trabucchi G, Girardi N, Marini I, Vergnani L, Caredda M, et al. Group psychoeducation normalizes cortisol awakening response in stabilized bipolar patients under pharmacological maintenance treatment. Psychother Psychosom 2013; 82: 264-266, doi: 10.1159/0003 48609.

19. Ice GH, Katz-Stein A, Himes J, Kane RL. Diurnal cycles of salivary cortisol in older adults. Psychoneuroendocrinology 2004; 29: 355-370, doi: 10.1016/S0306-4530(03)00034-9.

20. Ghiciuc CM, Dima-Cozma CL, Pasquali V, Renzi P, Simeoni $S$, Lupusoru CE, et al. Awakening responses and diurnal fluctuations of salivary cortisol, DHEA-S and $\alpha$-amylase in healthy male subjects. Neurondocrinol Lett 2011; 32: $475-480$

21. Sjörs A, Ljung $T$, Jonsdottir IH. Long-term follow-up of cortisol awakening response in patients treated for stressrelated exhaustion. BMJ Open 2012; 2: pii: e001091, doi: 10.1136/bmjopen-2012-001091.

22. Kishi T. Heart failure as an autonomic nervous system dysfunction. J Cardiol 2012; 59: 117-122, doi: 10.1016/ j.jjcc.2011.12.006.

23. Shen MJ, Zipes DP. Role of the autonomic nervous system in modulating cardiac arrhythmias. Circ Res 2014; 114 : 1004-1021, doi: 10.1161/CIRCRESAHA.113.302549.

24. DeCaro JA. Methodological considerations in the use of salivary alpha-amylase as a stress marker in field research. Am J Hum Biol 2008; 20: 617-619, doi: 10.1002/ ajhb.20795.

25. Bosch JA, Veerman EC, de Geus EJ, Proctor GB. $\alpha$-amylase as a reliable and convenient measure of sympathetic activity: don't start salivating just yet! Psychoneuroendocrinology 2011; 36: 449-453, doi: 10.1016/j.psyneuen.2010.12.019.

26. Schumacher $S$, Kirschbaum $C$, Fydrich $T$, Ströhle A. Is salivary alpha-amylase an indicator of autonomic nervous system dysregulations in mental disorders? A review of preliminary findings and the interactions with cortisol. Psychoneuroendocrinology 2013; 38: 729-743, doi: 10.1016/ j.psyneuen.2013.02.003.

27. Grant MJ, Booth A. A typology of reviews: an analysis of 14 review types and associated methodologies. Health Info Libr J 2009; 26: 91-108, doi: 10.1111/j.1471-1842.2009.00848.x.

28. Brydon L, Strike PC, Bhattacharyya MR, Whitehead DL, McEwan J, Zachary I, et al. Hostility and physiological responses to laboratory stress in acute coronary syndrome patients. J Psychosom Res 2010; 68: 109-116, doi: 10.1016/ j.jpsychores.2009.06.007.

29. Filaire E, Portier H, Massart A, Ramat L, Teixeira A. Effect of lecturing to 200 students on heart rate variability and alphaamylase activity. Eur J Appl Physiol 2010; 108: 1035-1043, doi: 10.1007/s00421-009-1310-4.

30. Hamidovic A, Childs E, Conrad M, King A, de Wit H. Stressinduced changes in mood and cortisol release predict mood effects of amphetamine. Drug Alcohol Depend 2010; 109: 175-180, doi: 10.1016/j.drugalcdep.2009.12.029.

31. Looser RR, Metzenthin P, Helfricht S, Kudielka BM, Loerbroks A, Thayer JF, et al. Cortisol is significantly correlated with cardiovascular responses during high levels of stress in critical care personnel. Psychosom Med 2010; 72: 281-289, doi: 10.1097/PSY.0b013e3181d35065.

32. Smeets T. Autonomic and hypothalamic-pituitary-adrenal stress resilience: Impact of cardiac vagal tone. Biol Psychol 2010; 84: 290-295, doi: 10.1016/j.biopsycho.2010.02.015.

33. Strahler J, Mueller A, Rosenloecher F, Kirschbaum C, Rohleder N. Salivary alpha-amylase stress reactivity across different age groups. Psychophysiology 2010; 47:587-595, doi: 10.1111/j.1469-8986.2009.00957.x.

34. Bostock S, Hamer M, Wawrzyniak AJ, Mitchell ES, Steptoe A. Positive emotional style and subjective, cardiovascular and cortisol responses to acute laboratory stress. Psychoneuroendocrinology 2011; 36: 1175-1183, doi: 10.1016/ j.psyneuen.2011.02.009.

35. Gallina S, Di Mauro M, D'Amico MA, D'Angelo E, Sablone A, Di Fonso A, et al. Salivary chromogranin A, but not $\alpha$-amylase, correlates with cardiovascular parameters during high-intensity exercise. Clin Endocrinol 2011; 75: 747-752, doi: 10.1111/j.1365-2265.2011.04143.x.

36. Juster RP, Sindi S, Marin MF, Perna A, Hashemi A, Pruessner JC, et al. A clinical allostatic load index is associated with burnout symptoms and hypocortisolemic profiles in healthy workers. Psychoneuroendocrinology 2011; 36: 797-805, doi: 10.1016/j.psyneuen.2010.11.001.

37. Simeoni S, Biselli R, D'Amelio R, Rocca B, Lattanzio S, Mucci $L$, et al. Stress-induced salivary cortisol secretion during hypobaric-hypoxia challenge and in vivo urinary thromboxane production in healthy male subjects. Stress 2011; 14: 282-289, doi: 10.3109/10253890.2010.545458.

38. van Leeuwen N, Bellingrath $\mathrm{S}$, de Kloet ER, Zitman FG, DeRijk RH, Kudielka BM, et al. Human mineralocorticoid receptor (MR) gene haplotypes modulate MR expression and transactivation: implication for the stress response. Psychoneuroendocrinology 2011; 36: 699-709, doi: 10.1016/ j.psyneuen.2010.10.003.

39. Wardle MC, Munafò MR, de Wit H. Effect of social stress during acute nicotine abstinence. Psychopharmacology 2011; 218: 39-48, doi: 10.1007/s00213-010-2150-y.

40. Andrews J, D'Aguiar C, Pruessner JC. The combined dexamethasone/TSST paradigm - a new method for Psychoneuroendocrinology. PLoS One 2012; 7: e38994, doi: 10.1371/journal.pone.0038994.

41. Arhakis A, Menexes G, Coolidge T, Kalfas S. Heart rate, salivary $\alpha$-amylase activity, and cooperative behavior in previously naïve children receiving dentallocal anesthesia. Pediatr Dent 2012; 34: e225-230.

42. Chatterjee A, Harris SB, Leiter LA, Fitchett $\mathrm{DH}$, Teoh $\mathrm{H}$, Bhattacharyya OK, et al. Managing cardiometabolic risk in primary care: summary of the 2011 consensus statement. Can Fam Physician 2012; 58: 389-393.

43. Costa R, Salvador A. Associations between success and failure in a face-to-face competition and psychobiological parameters in young women. Psychoneuroendocrinology 2012; 37: 1780-1790, doi: 10.1016/j.psyneuen.2012.03.012.

44. Furlan NF, Gavião MB, Barbosa TS, Nicolau J, Castelo PM. Salivary cortisol, alpha-amylase and heart rate variation in 
response to dental treatment in children. $J$ Clin Pediatr Dent 2012; 37: 83-87, doi: 10.17796/jcpd.37.1.n32m21n08417v363.

45. Hamer M, Steptoe A. Cortisol responses to mental stress and incident hypertension in healthy men and women. $J$ Clin Endocrinol Metab 2012; 97: E29-E34, doi: 10.1210/jc. 2011-2132.

46. Jones A, McMillan MR, Jones RW, Kowalik GT, Steeden JA, Deanfield JE, et al. Adiposity is associated with blunted cardiovascular, neuroendocrine and cognitive responses to acute mental stress. PLoS One 2012; 7: e39143, doi: 10.1371/journal.pone.0039143.

47. Maruyama $\mathrm{Y}$, Kawano $A$, Okamoto $S$, Ando $T$, Ishitobi $Y$, Tanaka $Y$, et al. Differences in salivary alpha-amylase and cortisol responsiveness following exposure to electrical stimulation versus the Trier Social Stress Tests. PLoS One 2012; 7: e39375, doi: 10.1371/journal.pone.0039375.

48. Mueller A, Strahler J, Armbruster D, Lesch KP, Brocke B, Kirschbaum C. Genetic contributions to acute autonomic stress responsiveness in children. Int J Psychophysiol 2012; 83: 302-308, doi: 10.1016/j.jpsycho.2011.11.007.

49. Nedeljkovic M, Ausfeld-Hafter B, Streitberger K, Seiler R, Wirtz $\mathrm{PH}$. Taiji practice attenuates psychobiological stress reactivity - a randomized controlled trial in healthy subjects. Psychoneuroendocrinology 2012; 37: 1171-1180, doi: 10. 1016/j.psyneuen.2011.12.007.

50. Phillips AC, Roseboom TJ, Carroll D, de Rooij SR. Cardiovascular and cortisol reactions to acute psychological stress and adiposity: cross-sectional and prospective associations in the Dutch Famine Birth Cohort Study. Psychosom Med 2012; 74: 699-710, doi: 10.1097/PSY.0b0 $13 \mathrm{e} 31825 \mathrm{e} 3 \mathrm{~b} 91$.

51. Seldenrijk A, Hamer M, Lahiri A, Penninx BW, Steptoe A. Psychological distress, cortisol stress response and subclinical coronary calcification. Psychoneuroendocrinology 2012; 37: 48-55, doi: 10.1016/j.psyneuen.2011.05.001.

52. Tanaka $\mathrm{Y}$, Ishitobi $\mathrm{Y}$, Maruyama $\mathrm{Y}$, Kawano $\mathrm{A}$, Ando $\mathrm{T}$, Imanaga $J$, et al. Salivary $\alpha$-amylase and cortisol responsiveness following electrical stimulation stress in panic disorder patients. Neurosci Res 2012; 73: 80-84, doi: 10.1016/ j.neures.2012.01.006.

53. Wong IS, Ostry AS, Demers PA, Davies HW. Job strain and shift work influences on biomarkers and subclinical heart disease indicators: a pilot study. J Occup Environ Hyg 2012; 9: 467-477, doi: 10.1080/15459624.2012.693831.

54. Al'Absi M, Khalil NS, Al Habori M, Hoffman R, Fujiwara K, Wittmers L. Effects of chronic khat use on cardiovascular, adrenocortical, and psychological responses to stress in men and women. Am J Addict 2013; 22: 99-107, doi: 10.1111/ j.1521-0391.2013.00302.x.

55. Fisher AJ, Newman MG. Heart rate and autonomic response to stress after experimental induction of worry versus relaxation in healthy, high-worry, and generalized anxiety disorder individuals. Biol Psychol 2013; 93: 65-74, doi: 10.1016/j.biopsycho.2013.01.012.

56. Jones A, McMillan MR, Jones RW, Kowalik GT, Steeden JA, Pruessner JC, et al. Habitual alcohol consumption is associated with lower cardiovascular stress responses - a novel explanation for the known cardiovascular benefits of alcohol? Stress 2013; 16: 369-376, doi: 10.3109/10253 890.2013.777833.
57. Lazzarino Al, Hamer M, Gaze D, Collinson P, Steptoe A. The association between cortisol response to mental stress and high-sensitivity cardiac troponin T plasma concentration in healthy adults. J Am Coll Cardiol 2013; 62: 1694-1701, doi: 10.1016/j.jacc.2013.05.070.

58. Nyklíček I, Mommersteeg PM, Van Beugen S, Ramakers C, Van Boxtel GJ. Mindfulness-based stress reduction and physiological activity during acute stress: a randomized controlled trial. Health Psychol 2013; 32: 1110-1113, doi: 10.1037/a0032200.

59. Jayasinghe SU, Torres SJ, Nowson CA, Tilbrool AJ, Turner Al. Physiological responses to psychological stress: importance of adiposity in men aged 50-70 years. Endocr Connect 2014; 3: 110-119, doi: 10.1530/EC-14-0042.

60. Klaperski S, von Dawans B, Heinrichs M, Fuchs R. Effects of a 12-week endurance training program on the physiological response to psychosocial stress in men: a randomized controlled trial. J Behav Med 2014; 37: 1118-1133, doi: 10.1007/s10865-014-9562-9.

61. Klumbies E, Braeuer D, Hoyer J, Kirschbaum C. The reaction to social stress in social phobia: discordance between physiological and subjective parameters. PLoS One 2014; 9: e105670, doi: 10.1371/journal.pone.0105670.

62. Krishnaveni GV, Veena SR, Jones A, Bhat DS, Malathi MP, Hellhammer D, et al. Trier social stress test in Indian adolescents. Indian Pediatr 2014; 51: 463-467, doi: 10.1007/ s13312-014-0437-5.

63. Lucas-Thompson RG, Granger DA. Parent-child relationship quality moderates the link between marital conflict and adolescents' physiological responses to social evaluative threat. J Fam Psychol 2014; 28: 538-548, doi: 10.1037/ a0037328.

64. Steptoe A, Hackett RA, Lazzarino Al, Bostock S, La Marca $\mathrm{R}$, Carvalho LA, et al. Disruption of multisystem responses to stress in type 2 diabetes: investigating the dynamics of allostatic load. Proc Natl Acad Sci USA 2014; 111: 15693-15698, doi: 10.1073/pnas.1410401111.

65. Bibbey A, Carroll D, Ginty AT, Phillips AC. Cardiovascular and cortisol reactions to acute psychological stress under conditions of high versus low social evaluative threat: associations with the type D personality construct. Psychosom Med 2015; 77: 599-608, doi: 10.1097/PSY.0000000000000194.

66. De Pero R, Cibelli G, Cortis C, Sbriccoli P, Capranica L, Piacentini MF. Stress related changes during TeamGym competition. J Sports Med Phys Fitness 2016; 56 : 639-647.

67. Ghiciuc CM, Dima-Cozma LC, Bercea RM, Lupusoru CE, Mihaescu T, Cozma S, et al. Imbalance in the diurnal salivary testosterone/cortisol ratio in men with severe obstructive sleep apnea: an observational study. Braz $J$ Otorhinolaryngol 2015; 82: 529-535, doi: 10.1016/j.bjorl. 2015.09.004.

68. Krishnaveni GV, Veena SR, Jones A, Srinivasan K, Osmond $\mathrm{C}$, Karat SC, et al. Exposure to maternal gestational diabetes is associated with higher cardiovascular responses to stress in adolescent indians. J Clin Endocrinol Metab 2015; 100: 986-993, doi: 10.1210/jc.2014-3239.

69. O'Donnell E, Landolt K, Hazi A, Dragano N, Wright BJ. An experimental study of the job demand-control model with measures of heart rate variability and salivary alpha-amylase: Evidence of increased stress responses to increased break 
autonomy. Psychoneuroendocrinology 2015; 51: 24-34, doi: 10.1016/j.psyneuen.2014.09.017.

70. Patacchioli FR, Ghiciuc CM, Bernardi M, Dima-Cozma LC, Fattorini L, Squeo MR, et al. Salivary $\alpha$-amylase and cortisol after exercise in menopause: influence of long-term HRT. Climacteric 2015; 20: 1-20, doi: 10.3109/13697137.2015. 1008444.

71. Skoluda N, Strahler J, Schlotz W, Niederberger L, Marques $\mathrm{S}$, Fischer $\mathrm{S}$, et al. Intra-individual psychological and physiological responses to acute laboratory stressors of different intensity. Psychoneuroendocrinology 2015; 51: 227-236, doi: 10.1016/j.psyneuen.2014.10.002.

72. Sripongngam $T$, Eungpinichpong $W$, Sirivongs $D$, Kanpittaya $\mathrm{J}$, Tangvoraphonkchai K, Chanaboon S. Immediate effects of traditional Thai massage on psychological stress as indicated by salivary alpha-amylase levels in healthy persons. Med Sci Monit Basic Res 2015; 21: 216-221, doi: 10.12659/ MSMBR.894343.

73. Hall DL, Blyler D, Allen D, Mishel MH, Crandell J, Germino $\mathrm{BB}$, et al. Predictors and patterns of participants adherence to a cortisol collection protocol. Psychoneuroendocrinology 2011; 36: 540-546, doi: 10.1016/j.psyneuen.2010.08.008.

74. Inder WJ, Dimeski G, Russell A. Measurement of salivary cortisol in 2012 - laboratory techniques and clinical indications. Clin. Endocrinol 2012; 77: 645-651, doi: 10.1111/ j.1365-2265.2012.04508.x.

75. Sánchez BN, Wu M, Raghunathan TE, Diez-Roux AV. Modeling the salivary cortisol profile in population research: the multi-ethnic study of atherosclerosis. Am J Epidemiol 2012; 176: 918-928, doi: 10.1093/aje/kws182.

76. Nater UM, Hoppmann CA, Scott SB. Diurnal profiles of salivary cortisol and alpha-amylase change across the adult lifespan: evidence from repeated daily life assessments. Psychoneuroendocrinology 2013; 38: 3167-3171, doi: 10.1016/j.psyneuen.2013.09.008.

77. Russell E, Kirschbaum C, Laudenslager ML, Stalder T, de Rijke Y, van Rossum EF, et al. Toward standardization of hair cortisol measurement: results of the first international interlaboratory round robin. Ther Drug Monit 2015; 37: 71-75, doi: 10.1097/FTD.0000000000000148.

78. Stalder T, Kirschbaum C, Kudielka BM, Adam EK, Pruessner JC, Wüst S, et al. Assessment of the cortisol awakening response: Expert consensus guidelines. Psychoneuroendocrinology 2016; 63: 414-432, doi: 10.1016/j.psyneuen. 2015.10.010.
79. Tsatsoulis A, Fountoulakis S. The protective role of exercise on stress system dysregulation and comorbidities. Ann N Y Acad Sci 2006; 1083: 196-213, doi: 10.1196/annals. 1367.020

80. Seeman T, Gruenewald T, Karlamangla A, Sidney S, Liu K, McEwen B, et al. Modeling multisystem biological risk in young adults: The Coronary Artery Risk Development in Young Adults Study. Am J Hum Biol 2010; 22: 463-472, doi: 10.1002/ajhb.21018.

81. Lambert EA, Lambert GW. Stress and its role in sympathetic nervous system activation in hypertension and the metabolic syndrome. Curr Hypertens Rep 2011; 13: 244-248, doi: 10.1007/s11906-011-0186-y.

82. Dima-Cozma LC, Patacchioli FR, Ghiciuc CM, Szalontay A, Mitu F, Azoicăi D. Current perspectives in stress research and cardiometabolic risk. Rev Cercet Interv So 2014; 45: 175-188.

83. Baughman P, Andrew ME, Burchfiel CM, Fekedulegn D, Hartley TA, Violanti JM, et al. High-protein meal challenge reveals the association between the salivary cortisol response and metabolic syndrome in police officers. Am J Hum Biol 2016; 28: 138-144, doi: 10.1002/ajhb.22748.

84. Vining RF, McGinley RA, Maksvytis JJ, Ho KY. Salivary cortisol: a better measure of adrenal cortical function than serum cortisol. Ann Clin Biochem 1983; 20: 329-335, doi: 10.1177/000456328302000601.

85. An K, Salyer J, Brown RE, Kao HS, Starkweather A, Shim I. Salivary biomarkers of chronic psychosocial stress and CVD risks: a systematic review. Biol Res Nurs 2016;18: 241-263, doi: $10.1177 / 1099800415604437$.

86. Lucini D, Riva S, Pizzinelli P, Pagani M. Stress management at the worksite: reversal of symptoms profile and cardiovascular dysregulation. Hypertension 2007; 49: 291-297, doi: 10.1161/01.HYP.0000255034.42285.58.

87. Sung J, Woo JM, Kim W, Lim SK, Chung EJ. The effect of cognitive behavior therapy-based "forest therapy" program on blood pressure, salivary cortisol level, and quality of life in elderly hypertensive patients. Clin Exp Hypertens 2012; 34: 1-7, doi: 10.3109/10641963.2011.618195.

88. Corey SM, Epel E, Schembri M, Pawlowsky SB, Cole RJ, Araneta MR, et al. Effect of restorative yoga vs. stretching on diurnal cortisol dynamics and psychosocial outcomes in individuals with the metabolic syndrome: the PRYSMS randomized controlled trial. Psychoneuroendocrinology 2014; 49: 260-271, doi: 10.1016/j.psyneuen.2014.07.012. 